\title{
A revised description of Synodontella zambezensis Douëllou et Chishawa, 1995 (Monogenea: Ancyrocephalidae) from the gills of Synodontis zambezensis (Siluriformes: Mochokidae) from South Africa
}

\author{
M. E. RAPHAHLELO', I. PŘIKRYLOVÁ $1,2,3$, M. M. MATLA', J. THERON, W. J. LUUS-POWELL'1
}
${ }^{1}$ Department of Biodiversity, University of Limpopo, Private Bag X1106, Sovenga 0727, South Africa; ${ }^{2}$ Water Research Group (Ecology), Unit for Environmental Sciences and Management, Potchefstroom Campus, North West University, Private Bag X6001,
Potchefstroom, 2520, South Africa; ${ }^{3}$ Department of Botany and Zoology, Faculty of Science, Masaryk University, Kotlárská 2, 61137 Brno, Czech Republic, E-mail: ivaprik@sci.muni.cz; ${ }^{4}$ Aquaculture Research Unit, University of Limpopo, Private Bag X1106, Sovenga 0727 , South Africa

Article info

Received July 19, 2016

Accepted October 19, 2016

\section{Summary}

This study supplements the original description of Synodontella zambezensis Douëllou et Chishawa, 1995 and represents a new geographical record for this parasite from Synodontis zambezensis from South Africa. The revision is based on morphometric characteristics and molecular data. Characterisation of LSU, partial SSU and ITS1 rDNA represents a first record of DNA sequencing for Synodontella species.

Keywords: Monogenea; Synodontella zambezensis; Synodontis; revised description; molecular phylogeny; South Africa

\section{Introduction}

Aquaculture, one of the fastest growing industries in the world, continues to play a key role in the provision of sustainable food security (Boane et al., 2008; Lima dos Santos \& Howgate, 2011). Members of the catfish family Mochokidae are amongst the most important teleost species suitable for aquaculture, with species of Synodontis Cuvier, 1817 being of the great commercial importance (Reed et al., 1967). Larger Synodontis species are important food fishes in many parts of Africa (Friel \& Vigliotta, 2006; Koblmüller et al., 2006), while others may be traded as ornamental aquarium fish due to their coloration (Ofori-Danson, 1992; Bruwer \& Van Der Bank, 2002). The known Synodontis species from southern Africa are Synodontis zambezensis Peters, 1852; Synodontis nigromaculatus Boulenger, 1905; Synodontis woosnami Boulenger, 1911; Synodontis macrostoma Skelton et White, 1990; Synodontis thamalakanensis Fowler, 1935; Synodontis vanderwaali Skelton et White, 1990; Synodontis leopardinus Pellegrin, 1914; Synodontis macrostigma Boulenger, 1911 and Synodontis nebulosus Peters, 1852 (Skelton, 2001).
Research on parasitic infections, more especially monogenean infections, is of relevance in order to avoid epizootics associated with cultured species (Buchmann \& Lindenstrøm, 2002). To date, only five species of Synodontella Dossou et Euzet, 1993 have been reported from species of Synodontis in Africa (Douëllou \& Chishawa, 1995; Lim et al., 2001). These are: Synodontella arcopenis Dossou et Euzet, 1993 from Synodontis sorex Gunther, 1864 in Bénin and Mali; Synodontella davidi Dossou et Euzet, 1993 from Synodontis membranaceus (Geoffroy et Hilaire, 1809) in Mali; Synodontella melanoptera Dossou et Euzet, 1993 from Synodontis melanopterus Boulenger, 1902 in Bénin; Synodontella synodontii (Paperna et Thurston, 1968) from Synodontis victoriae Boulenger, 1906 in Uganda and Synodontella zambezensis Douëllou et Chishawa, 1995 from Synodontis zambezensis in Zimbabwe. So far no data are available on monogeneans of Synodontis zambezensis in South Africa. The present study provides the first record of a Synodontella species from South Africa, provides the first record of molecular data of this genus and present revised description of Synodontella zambezensis. 
Table 1. Host characters, weight $(\mathrm{g})$ and length $(\mathrm{cm})$; total number of parasites and the prevalence, mean intensity and range of intensity of infection for Synodontella zambezensis in Synodontis zambezensis examined from Flag Boshielo Dam



$n$, number of fish examined

\section{Material and Methods}

In total, 107 specimens of Synodontis zambezensis were collected from February 2012 to January 2013, from Flag Boshielo Dam (24 49' 05.7"S; $029^{\circ} 24^{\prime}$ '50.9" E) using a combination of conventional angling gear and gill nets. The fish were weighed $(\mathrm{g})$ and measured for total length $(\mathrm{cm})$. All details on the sample sizes and parasitic infection are given in Table 1. Specimens were kept in aerated holding tanks to ensure the well-being of the specimens, until each individual host was examined. Gills were removed and examined for the presence of monogeneans using a stereomicroscope. Specimens were mounted in either glycerine jelly or ammonium picrate-glycerine (GAP) solution as described by Malmberg (1957) and used for morphological measurements of the anchors, marginal hooks and male copulatory organ (MCO). Specimens were studied and measured under Nomarski Differential Contrast microscope (Olympus BX50) fitted with a camera and imaging software (Soft Imaging System GMBH 1986), a drawing tube and a calibrated eye piece. Drawings were digitized and arranged using Adobe Photoshop CS6 and Adobe Illustrator CS6 version 13.0. Measurements of parasites' bodies and hard parts were done according to Gussev in Bychovskaya-Pavlovskaya et al. (1962) and Dossou and Euzet (1993). All measurements are given in micrometres and are presented as the mean with the range in parentheses. For a comparative study of Synodontella zambezensis, the type material was obtained from the National Museum of Natural History, Paris, France (paratype MNHN 173 HF).

Selected specimens were cut transversally; the posterior part of the parasite's body was fixed in $96 \%$ ethanol (Lach-Ner, Nerato- vice, Czech Republic) for molecular analyses and the anterior part fixed in GAP for morphological analyses.

Preservation ethanol was evaporated in a vacuum centrifuge, after which DNA was extracted using the Qiagen Blood and Tissue Isolation kit, according to the manufacturer's protocol (Qiagen, Hilden, Germany). DNA was eluted in $50 \mu \mathrm{l}$. The partial sequence of the small subunit of ribosomal DNA (SSU rDNA) and the entire first internal transcribed spacer (ITS1) region were amplified in one round using S1 and IR8 primers (Šimková et al., 2003) according to protocol of Mendlová et al. (2012) and the large subunit of ribosomal DNA (LSU rDNA) region was amplified using primers C1 and D2 (Hassouna et al., 1984) using the protocol described in Mendlová et al. (2012). Subsequently, $5 \mu$ l of PCR product was visualized on Gold View stained agarose gel (1\%) and the remaining $20 \mu \mathrm{l}$ was purified using the High Pure PCR Product Purification Kit (Roche, Basel, Switzerland). Sequencing, using identical primers used in the initial amplification, was carried out with the Big Dye Chemistry Cycle Sequencing Kit v.3.1 and an ABI 3130 Genetic Analyser automated sequencer (Applied Biosystems, Foster City, California, United States). The obtained sequences were aligned using Clustal W Multiple alignment (Thompson et al., 1994) applied MEGA6 (Tamura et al., 2013) to confirm their identity and length. Obtained nucleic acid sequences of SSU and LSU were subjected to Basic Local Alignment Search Tool searches (BLAST searches) (Zhang et al., 2000) to identify any matches or closely related species. From the resulted list of "related" species based on SSU sequence search, the following sequences of parasites of various Siluriformes fishes were picked up and used for the phylogram reconstruction: Cleidodiscus pricei Mueller, 1936 (AJ490168), Pseudancylodis- 
coides sp. 1 (EF100566), Pseudancylodiscoides sp. 2 (EF100565), Quadriacanthus sp. (HG491496), Schilbetrema sp. (HG491495), Thaparocleidus siluri (Zandt, 1924) (AJ490164) and Thaparocleidus vistulensis (Sivak, 1932) (AJ490165). Lamellodiscus erythrini Euzet et Olivier, 1966 (AJ276440) was selected as the outgroup. Retrieved sequences were aligned using Clustal W Multiple alignment applied MEGA6. The estimation of genetic distances between species sequences, and a simple phylogenetic comparisons applying Neighbour joining (NJ) and Maximum Likelihood (ML) statistics under Kimura-two parameter model (Kimura, 1980) with gamma shape parameter $(\Gamma=0.14)$ were performed in MEGA6 using bootstrap resampling procedure with 1000 replicates. The optimal evolutionary model was estimated ibidem. Bayesian inference (BI), using the GTR $+\Gamma$ model, was implemented in MrBayes v.3 (Huelsenbeck \& Ronquist, 2001; Ronquist \& Huelsenbeck, 2003). Posterior probabilities were calculated over $5.10^{5}$ generations, sampling the Markov chain every 100 generations. One-fourth of the samples were discarded as "burn-in".

A

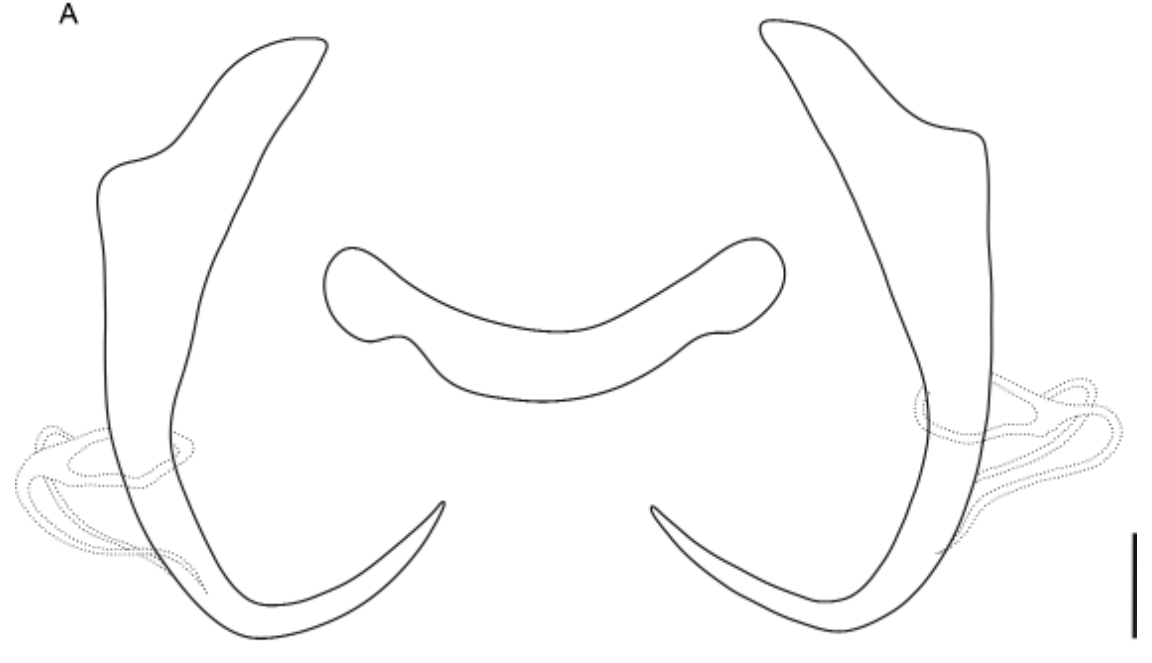

B



C

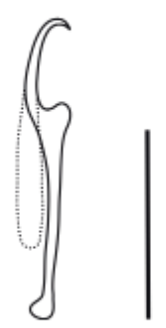

D

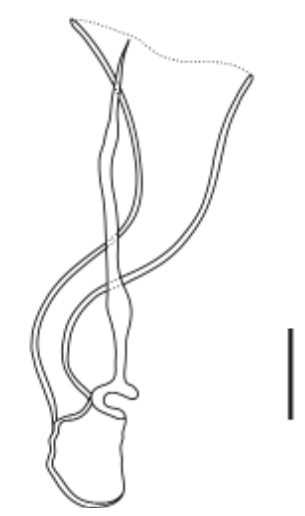

Fig. 1. The sclerotized hard parts of Synodontella zambezensis;

A - Dorsal anchors with dorsal bar, B - Ventral anchors with ventral transverse bar, C - Marginal hook and D - MCO. Scale bars: $10 \mu \mathrm{m}$. 


\section{Results}

A total of 10875 parasites were recovered from the host specimens throughout the study period. Parasites were not sampled during May, August and October, as no host specimens were collected. For the month of September only one host specimen was caught and was not considered. Prevalence of infection was the same (100\%) throughout the investigation (Table 1), but the mean intensity of infection varied, with the highest intensity of infection observed in December, while the lowest intensity of infection was recorded in March. Data on host characters (weight and total length) are given in Table 1.

Synodontella zambezensis Douëllou et Chishawa, 1995 (Fig. 1) Type-host: Synodontis zambezensis.

Site on host: Gills.

Type locality: Lake Kariba (Sanyati basin), Zimbabwe. Locality (Present study): Flag Boshielo Dam (Olifants River System), South Africa.

Type material: Deposited in National Museum of Natural History, Paris, France (MNHN 149 HF).

Material deposited: Three voucher specimens (IPCAS; Coll. No.M619) are deposited in the helminthological collection held at the Institute of Parasitology, Academy of Sciences of the Czech Republic, České Budĕjovice.

Molecular sequenced data:

The $793-872$ bp long fragments of SSU region were successfully obtained from 12 specimens. The entire sequence was identical from all 12 specimens. Four samples were randomly selected and subsequently amplified for LSU region. The length of obtained sequences was $657-696 \mathrm{bp}$ and all four sequences were identical in the entire length. The longest fragments for both regions were submitted to European Nucleotide Archive (ENA) under accession numbers LT220021 and LT220022, for SSU and LSU, respectively.

Morphological description (Based on 30 mounted specimens) Body length 558 - 865; width 126.3 - 196.3; pharynx diameter 40 - 52.5. Four eye-spots present, anterior pair smaller than posterior pair. Two pairs of anchors, dorsal pair larger, with base enlarged and "foot shaped"; ventral pair smaller with projection extending along outer root towards the shaft. Measurements of the hard parts are given in Table 2. Two bars present, dorsal bar more or less V-shaped, ventral bar T-shaped. Seven pairs of marginal hooks of equal size. Male copulatory organ (MCO) consisting of copulatory tube (longer: 42.5 - 50) and accessory piece (shorter and thicker: 28.8 - 32.5), both arising from an oval shaped base.

\section{Comments:}

The re-examination of Synodontella zambezensis type material has confirmed the current study species identification. Comparative drawings of haptoral sclerites and MCO of specimens from the present study and those of the type material is shown in Fig. 2. The general morphology of structures from the present study is similar to those of original description (Douëllou \& Chishawa, 1995). Nevertheless, small differences were observed. The measurements of the features of haptoral hard parts obtained during the current study overlap with those reported by Douëllou and Chishawa (1995) and the means of most features fit in the ranges presented ibidem.

The measurements of both dorsal anchor shaft and ventral anchor shaft from the current study provide additional information as these features were not measured in the original description. Synodontella zambezensis can be easily distinguished from Synodontella synodontii based on distinctively smaller haptoral structures (Table 2). Synodontella davidi has overall dimensions of both anchors slightly larger than Synodontella zambezensis but the length of the copulatory tubes is more than double the length. Synodontella zambezensis can be differentiated from Synodontella arcopenis by the dimensions of ventral anchors and ventral bar, which are larger in Synodontella arcopenis than in Synodontella zambezensis. The most measurements of hard parts of Synodontella melanoptera overlap with those of Synodontella zambezensis except for the total length of the ventral bar. These two species differ in the shape of ventral anchors: those of Synodontella melanoptera (see Dossou \& Euzet, 1993, Fig. 3) have a more slender appearance and distinctively pronounced inner root.

\section{Molecular characterization}

No variability was observed in either SSU or LSU sequences. Constructed SSU alignment was 477 bp long and contained 362 conservative and 115 variable sites of which 53 were parsimony informative. Phylogram based on SSU sequences of monogenean parasites of various fishes of Siluriformes shows the genus Schilbetrema Paperna et Thurston, 1968 to be a sister taxon to the genus Synodontella (Fig. 3). Other relationships between genera is difficult to present as the nodes received low supports, thus they have been collapsed. Some relationships between species included in the analyses can be inferred from uncorrected $p$-distances (Table. 3). The lowest differences in SSU sequences were observed between Thaparocleidus spp. and Pseudancylodiscoides spp. 5.0 - $5.7 \%$ which might indicate close relationship, while in between Synodontella zambezensis and Schilbetrema sp., which form well-supported cluster, $8 \%$ difference was found.

When LSU sequence was subjected to BLAST Search no close hit was found. The only close was Schilbetrema sp. (acc. num. KP056243) with very low query, only $54 \%$ and $84 \%$ coverage on comparing fragments.

\section{Discussion}

The genus Synodontella currently contains five known species: $S$. arcopenis, S. davidi, S. melanoptera; S. synodontii and S. zambezensis, and is host specific to species of mochokid catfishes. So far, these species have been recorded from six African countries, including results of the present study, and from just five host spe- 
1

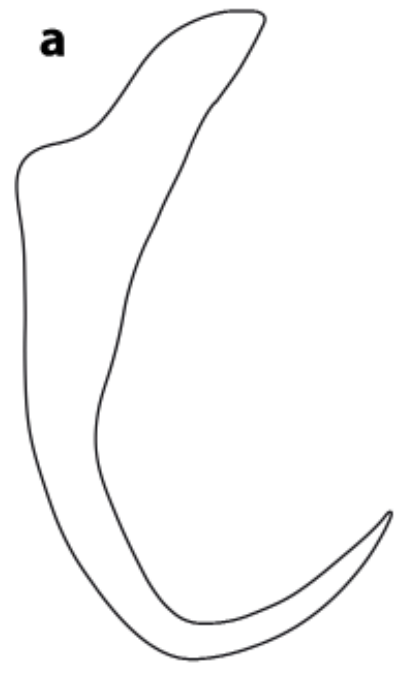

3

a

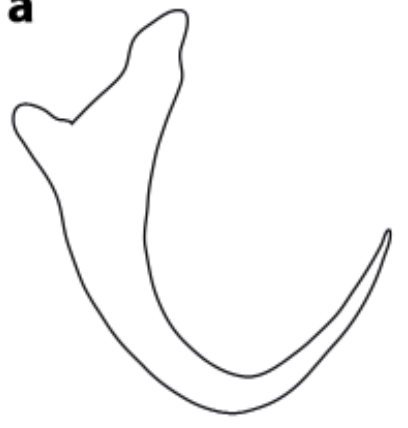

b

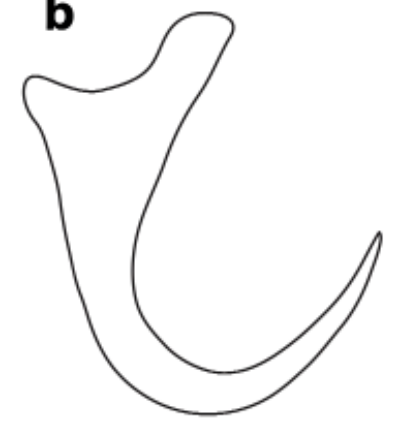

5

a
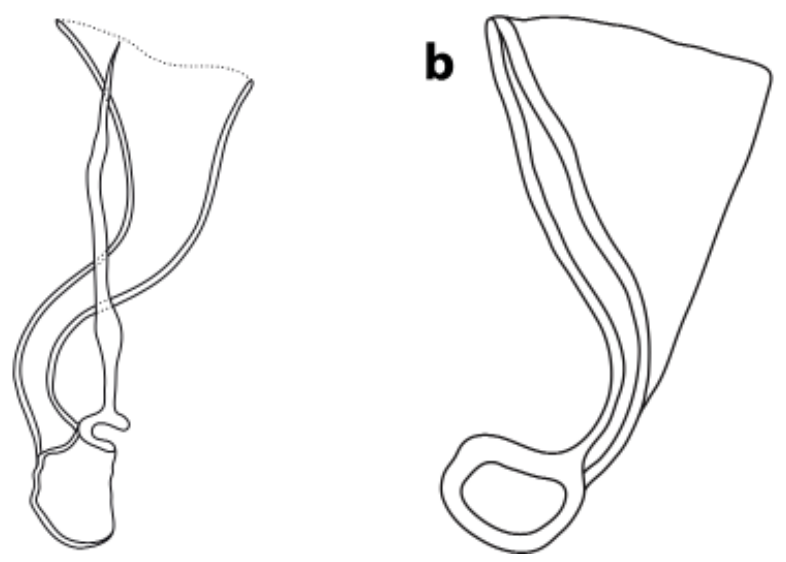

b
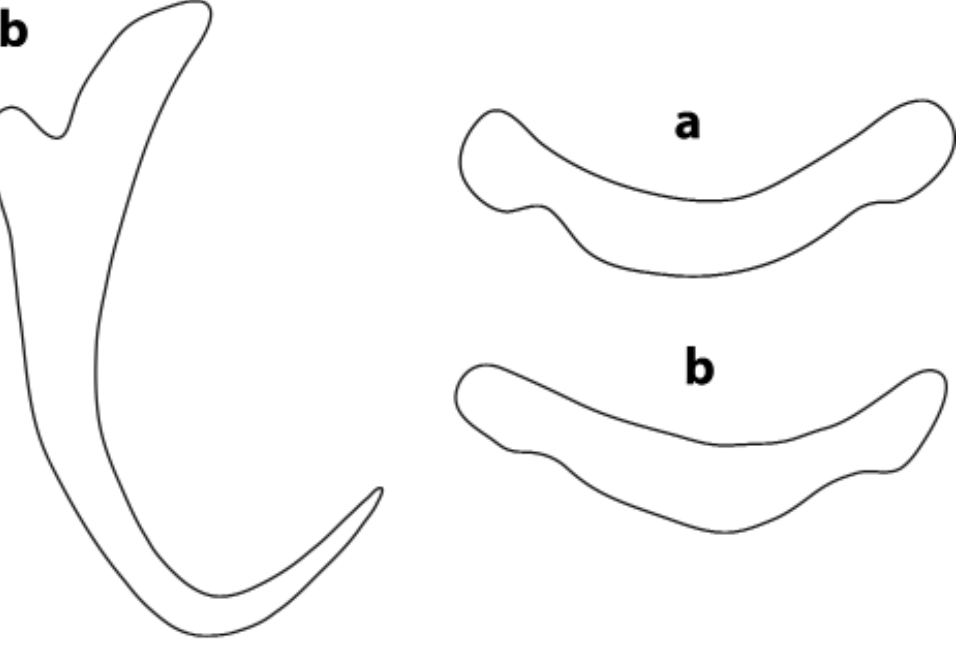

4


Fig. 2. Comparison of the sclerotized hard parts of Synodontella zambezensis; (a) specimens from current study and (b) paratype specimen. 1 - Dorsal anchors, 2 Dorsal bar, $3-$ Ventral anchors, $4-$ Ventral transverse bar and $5-$ MCO. Scale bar $=20 \mu \mathrm{m}$. 
Table 3. Uncorrected pair-wise genetic distances between species included in the phylogenetic analysis, for a 477 bp dataset

\begin{tabular}{|c|c|c|c|c|c|c|c|c|c|}
\hline & & 1 & 2 & 3 & 4 & 5 & 6 & 7 & 8 \\
\hline 1 & Synodontella zambezensis & & & & & & & & \\
\hline 2 & Schilbetrema sp. & 0.080 & & & & & & & \\
\hline 3 & Pseudancylodiscoides sp. 1 & 0.109 & 0.086 & & & & & & \\
\hline 4 & Pseudancylodiscoides sp. 2 & 0.111 & 0.084 & 0.006 & & & & & \\
\hline 5 & Thaparocleidus vistulensis & 0.107 & 0.088 & 0.057 & 0.050 & & & & \\
\hline 6 & Thaparocleidus siluri & 0.103 & 0.084 & 0.057 & 0.050 & 0.008 & & & \\
\hline 7 & Cleidodiscus pricei & 0.118 & 0.105 & 0.086 & 0.086 & 0.095 & 0.088 & & \\
\hline 8 & Quadriacanthus sp. & 0.120 & 0.101 & 0.084 & 0.082 & 0.065 & 0.065 & 0.109 & \\
\hline 9 & Lamellodiscus erythrini & 0.163 & 0.150 & 0.140 & 0.146 & 0.146 & 0.146 & 0.182 & 0.146 \\
\hline
\end{tabular}

cies (Khalil \& Polling, 1997). There are currently 131 recognized species in the genus Synodontis (Froese \& Pauly, 2015) and Synodontis accounts for about one-quarter of African catfish species (Koblmüller et al., 2006). Such high number of potential hosts for Synodontella species might indicate that species richness among this genus is much higher than we know now, especially taking into account that the known Synodontella species have been reported from only five host species of Synodontis. From the literature, only two studies have been undertaken on the genus Synodontella in southern Africa from Lake Kariba (Douëllou, 1992; Douëllou \& Chishawa, 1995).

The drawings given in Fig. 2 (present study) clearly show that the present specimens are identical with the type material of Douellou and Chishawa (1995). Despite slight differences in the shape of dorsal anchors found, there is no reason to consider the present material as a new species. The paratype specimen was observed

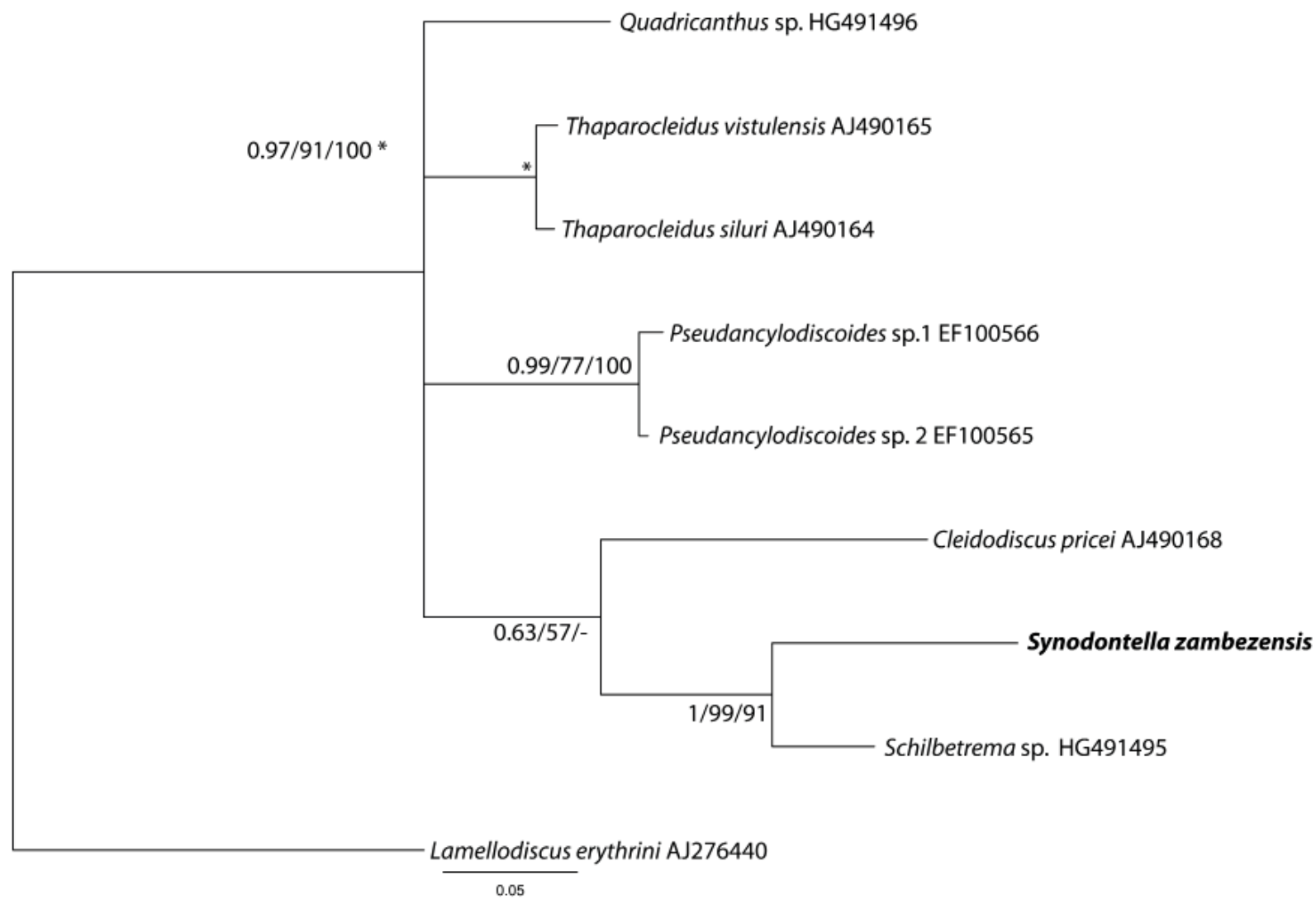

Fig. 3. Unrooted phylogram for parasites of Siluriformes hosts constructed from a 477 bp dataset of the partial of SSU rDNA and the entire ITS1 rDNA sequences. Statistical node support is shown as follow: Bayesian posterior probability/ maximum likelihood bootstrap/ Neighbour joining bootstrap. Branch lengths correspond to the expected number of substitutions per site under Bayesian inference. Sequence obtained in the present study is given in bold. 
to have a more protrude outer root. Unfortunately, the quality of paratype specimens were very low and thus some details on the structures were difficult to observe, especially for the composition of MCO. The different geographical origin might likely to have an influence on the variability in the shape of sclerotized structure.

Results presented in Table 1, prevalence of $100 \%$ at each sampling, show that Synodontella zambezensis is a very common parasite for Synodontis zambezensis. The highest infection level in December, with mean intensity of infection of 295.6, might be the result of higher temperatures during this study which is in favour of the development of the parasites. In addition, most fish species are more active during summer and they might occupy a wider range of the habitat, either through searching for food or mating activities. In South Africa, Mbokane et al. (2015) reported an increase of dactylogyrid monogeneans infection with an increase in water temperature. In European studies, Šimková et al. (2001) observed that the abundance of dactylogyrids species was affected by water temperature, with abundance being highest when the water temperature was also at its highest.

Prior to this study, no molecular data for Synodontella species was available. The effort to find the phylogenetic position of Synodontella species among dactylogyrid parasites of Siluriformes did not provide satisfying results. The SSU and LSU rDNA regions are often used for inferring phylogenies among various groups of dactylogyrids (Pouyaud et al., 2006; Wu et al., 2007; Mendlová et al., 2010; Šimková et al., 2013; Mendoza-Palmero et al., 2015). It has been shown in a recent study of Mendoza-Palmero et al. (2015) that parasites of different genera of various catfishes are not always closely related and create paraphyletic lineages. Dactylogyrids parasitizing Neotropical catfishes create clades with those from the Holarctic parasites of perciformes hosts and all others dactylogyrids of siluriforms with Palearctic, Ethiopian, Oriental and Neotropic form a separate clade (Mendoza-Palmero et al., 2015). The paraphyly of dactylogyrid genera is the most probable explanation for the finding of the present study. However, we included in our analysis of the closest "related" parasites based on the BLAST Search of available sequences in the database, from Fig. 3 it's evident that dactylogyrid genera of catfishes namely Quadriacanthus, Thaparocleidus Jain, 1952 and Pseudancylodiscoides Yamaguti, 1963 are not real relative to Synodontella, but the genus Schilbetrema most likely is. Some future studies focusing on DNA analysis of various African dactylogyrids parasitizing siluriform host would bring new interesting insight on it.

\section{Acknowledgements}

We are grateful to Mr. W.J. Smit, Dr. J.R. Sara, Dr. S. Tavakol, Ms. T.P. Ramalepe and Mr. N.M. Chabalala (Department of Biodiversity) and Dr L.J.C. Erasmus and Ms M.E. Mogashoa (Department of Physiology and Environmental Health) University of Limpopo, for the assistance with fish collection and fieldwork. This work is based on the research supported by the South African Research
Chairs Initiative of the Department of Science and Technology and National Research Foundation of South Africa (Grant No. 101054) and the University of Limpopo. Any opinion, finding and conclusion or recommendation expressed in this material is that of the author(s) and the NRF does not accept any liability in this regard. Molecular analyses were performed at the Department Botany and Zoology, Faculty of Science Masaryk University and were founded by the Grant Agency of the Czech Republic (grant number GBP505/12/G112).

\section{References}

Boane, C., Cruz, C., Saraiva, A. (2008): Metazoan parasites of Cyprinus carpio L.(Cyprinidae) from Mozambique. Aquaculture, 284: 59 - 61. DOI: 10.1016/j.aquaculture.2008.07.037

Bruwer, E.E., Van Der Bank, F. (2002): Biochemical genetic markers (hybrizymes) to identify Synodontis zambezensis $\times S$. nigromaculatus hybrids (Teleostei: Mochokidae). Biochem. Syst. Ecol., 30: 641 - 649

BuCHMANN, K., LINDENSTRøM, T. (2002): Interactions between monogenean parasites and their fish hosts. Int. J. Parasitol., 32: 309 $-319$

Dossou, C., Euzet, L. (1993): Synodontella n.g. (Monogenea, Ancyrocephalidae) parasites de Mochokidae africains du genre Synodontis Cuvier, 1817. Rev. Zool. Afr., 107: 175 - 185

DouËLlou, L. (1992): A survey of fish parasites in Lake Kariba. University of Zimbabwe, University Lake Kariba Research Station Bulletin 1/92: 1 - 71.

DouËllou, L., ChishaWA, A. (1995): Monogeneans of three Siluriform fish species in Lake Kariba, Zimbabwe. J. Afr. Zool., 109: 99 $-115$

FRIEL, J.P., VIGLIOTTA, T.R. (2006): Synodontis acanthoperca, a new species from the Ogôoué River system, Gabon with comments on spiny ornamentation and sexual dimorphism in mochokid catfishes (Siluriformes: Mochokidae). Zootaxa, 1125: 45 - 56

Froese, R., Pauly, D. (2015): FishBase. World Wide Web electronic publication, version 04/2015. Retrieved June 7, 2015 from http:// www.fishbase.org.

Gussev, A.V. (1962): In: E. Bychovskaya-Pavlovskaya, et al. (Eds). [Key to parasites of freshwater fish of the USSR]. Publishing House of Academy of Sciences of the USSR, Moscow-Leningrad: Nauka. 919 pp. (In Russian; English translation IPST, Ser. No. 1136, Jerusalem, 1964).

HuelsenBeCK, J.P., Ronquist, F. (2001): MrBayes: Bayesian inference of phylogenetic trees. Bioinformatics, 17: $754-755$

Hassouna, N., Mithot, B., Bachellerie, J.P. (1984): The complete nucleotide sequence of mouse $28 \mathrm{~S}$ rRNA gene. Implications for the process of size increase of the large subunit rRNA in higher eukaryotes. Nucleic Acids Res., 12: 3563 - 3583

KHaLIL, L.F., PoluING, L. (1997): Check list of the helminth parasites of African freshwater fishes. Department of Zoology/Biology, University of the North, Sovenga, South Africa, 185 pp. 
KIMURA, M. (1980): A simple method for estimating evolutionary rate of base substittitions through comparative studies on nucleotide sequences. J. Mol. Evol., 16: 111 - 120

Koblmüller, S., Sturmbauer, C., Verheyen, E., Meyer, A., SalzburgER, W. (2006): Mitochondrial phylogeny and phylogeography of East African squeaker catfishes (Siluriformes: Synodontis). BMC Evolutionary Biology, 6: 49. DOI: 10.1186/1471-2148-6-49

LIM, L., TIMofeeva, T., GiBSON, D. (2001): Dactylogyridean monogeneans of the siluriform fishes of the Old World. Syst. Parasitol., 50: 159 - 197

Lima Dos Santos, C.A.M., Howgate, P. (2011): Fishborne zoonotic parasites and aquaculture: A review. Aquaculture, 318: 253 - 261. DOI: 10.1016/j.aquaculture.2011.05.046

MALMBERG, G. (1957): [On the occurrence of Gyrodactylus on Swedish fishes.] Skrifterutgivna av Sodra Sveriges Fiskeriforening, (1956): 19 - 76 pp. (In Swedish, with description of species and a summary in English.)

Mbokane, E.M., Matla, M.M., Theron, J., Luus-Powell, W.J. (2015): Seasonal dynamics and occurrences of three Dactylogyrus species on the gills of three cyprinids at Nwanedi - Luphephe dams in Limpopo province, South Africa. Afr. Zool., 50(2): 119 - 125. DOI: 10.1080/15627020.2015.1021175

Mendlová, M., Desdevises, Y., Civáñová, K., Pariselle, A., Šimková, A. (2012): Monogeneans of West African cichlids fish: Evolution and Cophylogenetic Interactions. PLOS ONE 7, e37268. DOI: 10.1371/journal.pone.0037268

Mendlová, M., Pariselle, A., Vyskočllová, M., Šimková, A. (2010): Molecular phylogeny of monogeneans parasitizing African freshwater Cichlidae inferred from LSU rDNA sequences. Parasitol. Res., 107: 1405 - 1413. DOI: 10.1007/s00436-010-2008-6

Mendoza-Palmero, C.A., Blasco-Costa, I., Scholz, T. (2015): Molecular phylogeny of Neotropical monogeneans (Platyhelminthes: Monogenea) from catfishes (Siluriformes). Parasit. Vectors, 8: 164. DOI: 10.1186/s13071-015-0767-8

Ofori-Danson, P.K. (1992): Ecology of some species of catfish Synodontis (Pisces: Mochocidae) in the Kpong Headpond in Ghana. Environ. Biol. Fishes, 35: 49 - 61

Poll, M. (1971): Revision des Synodontis africains (famille Mochocidae). [Revision of Synodontis africains (family Mochocidae)]. Ann. Mus. R. Afr. Centr., Sci. Zool., 191: 1 - 497
Pouyaud, L., Desmarais, E., Deveney, M., Pariselle, A. (2006): Phylogenetic relationships among monogenean gill parasites (Dactylogyridea, Ancyrocephalidae) infesting tilapiine hosts (Cichlidae): Systematics and evolutionary implications. Mol. Phylogenet. Evol., 38: 241 - 249. DOI: 10.1016/j.ympev.2005.08.013

Reed, W., Burchard, J., Hopson, A., Jennes, J., Yaro, I. (1967): Fishes of northern Nigeria, Ministry of Agriculture Northern Nigeria. Gaskiya Corporation, Zaria, Nigeria. 226 pp.

Ronquist, F., HuelsenBECK, J. P. (2003): MrBayes 3: Bayesian phylogenetic inference under mixed models. Bioinformatics, 19(12): 1572 - 1574. DOI: 10.1093/bioinformatics/btg180

Šımková, A., Plaisance, L., Matějusová, I., Morand, S., Verneau, O. (2003): Phylogenetic relationships of the Dactylogyridae Bychowsky, 1933 (Monogenea: Dactylogyridea): the need for the systematic revision of the Ancyrocephalinae Bychowsky, 1937. Syst. Parasitol., 54(1): 1 - 11

Šimková, A., Sasal, P., Kadlec, D., Gelnar, M. (2001): Water temperature influencing dactylogyrid species communities in roach, Rutilus rutilus, in the Czech Republic. J. Helminthol., 75: 373 383. DOI: $10.1079 / \mathrm{JOH} 200176$

Šimková, A., Serbielle, C., Pariselle, A., Vanhove, M.P.M., Morand, S. (2013): Speciation in Thaparocleidus (Monogenea: Dactylogyridae) Parasitizing Asian Pangasiid Catfishes. Biomed Res. Int., 353956. DOI: $10.1155 / 2013 / 353956$

SKELTON, P.H. (2001): A complete guide to the freshwater fishes of Southern Africa. Halfway House, Cape Town, 395 pp.

Tamura, K., Stecher, G., Peterson, D., Filipski, A., Kumar, S. (2013): MEGA6: molecular evolutionary genetics analysis version 6.0. Mol. Biol. Evol., 30: 2725 - 2729. DOI: 10.1093/molbev/mst197 ThOMPSON, J.D., HIGGINS, D.G., GIBSON, T.J. (1994): CLUSTAL W: improving the sensitivity of progressive multiple sequence alignment through sequence weighting, position-specific gap penalties and weight matrix choice. Nucleic Acids Res., 22, 4673 - 4680

Wu, X.-Y., ZHu, X.-Q., XIE, M.-Q., LI, A.-X. (2007): The evaluation for generic-level monophyly of Ancyrocephalinae (Monogenea, Dactylogyridae) using ribosomal DNA sequence data. Mol. Phylogenet. Evol., 44: 530 - 544. DOI: 10.1016/j.ympev.2007.03.025 Zhang, Z., Schwartz, S., Wagner, L., Miller, W. (2000): A greedy algorithm for aligning DNA sequences. J. Comp. Biol., 7: 203 - 214 